\title{
Parasegmental appendage allocation in annelids and arthropods and the homology of parapodia and arthropodia Nikola-Michael Prpic
}

\author{
Address: Georg-August-Universität Göttingen, Johann-Friedrich-Blumenbach Institut für Zoologie und Anthropologie, Abteilung für \\ Entwicklungsbiologie, GZMB Ernst Caspari Haus, Justus-von-Liebig-Weg 11, 37077 Göttingen, Germany
}

Email: Nikola-Michael Prpic - nprpic@uni-goettingen.de

Published: 20 October 2008

Frontiers in Zoology 2008, 5:17 doi:10.1186/1742-9994-5-17
Received: I April 2008

Accepted: 20 October 2008

This article is available from: http://www.frontiersinzoology.com/content/5/1/17

(C) 2008 Prpic; licensee BioMed Central Ltd.

This is an Open Access article distributed under the terms of the Creative Commons Attribution License (http://creativecommons.org/licenses/by/2.0), which permits unrestricted use, distribution, and reproduction in any medium, provided the original work is properly cited.

\begin{abstract}
The new animal phylogeny disrupts the traditional taxon Articulata (uniting arthropods and annelids) and thus calls into question the homology of the body segments and appendages in the two groups. Recent work in the annelid Platynereis dumerilii has shown that although the set of genes involved in body segmentation is similar in the two groups, the body units of annelids correspond to arthropod parasegments not segments. This challenges traditional ideas about the homology of "segmental" organs in annelids and arthropods, including their appendages. Here I use the expression of engrailed, wingless and Distal-less in the arthropod Artemia franciscana to identify the parasegment boundary and the appendage primordia. I show that the early body organization including the appendage primordia is parasegmental and thus identical to the annelid organization and by deriving the different adult appendages from a common ground plan I suggest that annelid and arthropod appendages are homologous structures despite their different positions in the adult animals. This also has implications for the new animal phylogeny, because it suggests that Urprotostomia was not only parasegmented but also had parasegmental appendages similar to extant annelids, and that limb-less forms in the Protostomia are derived from limb-bearing forms.
\end{abstract}

\section{Findings}

Arthropods and annelids have their body divided into a series of repeated units that bear pairs of appendages in most cases. These body units and their appendages have long been regarded as homologous structures and have been the basis for uniting annelids and arthropods as sister taxa in the taxon Articulata [1]. The so-called "new animal phylogeny", however, does not support this close relationship between annelids and arthropods and rather places them in two different branches of protostome phylogeny termed Lophotrochozoa and Ecdysozoa, respectively [2]. This suggests that body segments and appendages in annelids and arthropods might have originated separately and are therefore not homologous. On the other hand recent results suggest that at least segmen- tation might have an ancient origin that predates or coincides with the origin of the Bilateria [3].

In arthropods the body units are first specified in a parasegmental register [4] and later these parasegments are transformed into segments by re-segmentation during embryonic development [5]. Intriguingly, recent work using the expression of the segmentation genes engrailed $(e n)$ and wingless $(w g)$ has demonstrated that re-segmentation does not occur in annelids and the body units in annelids thus remain parasegments $[6,7]$. This also makes annelid appendages (parapodia) parasegmental rather than segmental structures and this is further evidenced by the expression of the appendage marker Distal-less (Dll/ $D l x)$ [7]. This calls into question the homology between 
annelid parapodia and the appendages of arthropods (arthropodia). Here I show that in an arthropod species, the brine shrimp Artemia franciscana, the early body organisation including the limb primordia is identical to the annelid condition. This demonstrates that arthropodia like parapodia are initially parasegmental organs and suggests that both share a common evolutionary origin.

Artemia franciscana development includes a larval stage (nauplius) (Figure 1A). The nauplius consists of an anterior part, comprising the ocular region, labrum, first and second antenna and mandibles, and a posterior part, which is a more or less undifferentiated trunk. In nauplii at stage III (staging after [8]) this trunk region develops two bulges (boxed in red in Figure 1A) followed by a smooth region, the "growth cone". The reason for the two bulges is that there are already the mesodermal blocks forming beneath the ectoderm [8]. The large bulge contains, still in a single block, the mesoderm for several future segments (first and second maxillary, and first thoracic segment), the second smaller bulge contains the mesoderm for the second thoracic segment. These two bulges are thus the first morphological sign of subdivision in the trunk region. I used the expression of en [GenBank:X70939] and wg [EMBL:AM774593] to identify the location of parasegment boundaries in the trunk. en is expressed in the anterior portion of the smaller bulge and in the anterior part of the growth cone following the smaller bulge (Figure 1B). $w g$ is expressed at the posterior border of the large bulge and in the posterior portion of the smaller bulge (Figure 1C). In some specimens, that are further into stage III, the $w g$ stripe in the posterior part of the large bulge is separated from the morphological groove by about two cell diameters (Figure 1D). The significance of this is presently unclear. It could be a sign of the beginning resegmentation at this location or might be correlated with patterning mechanisms specific to the large bulge which is a complex structure comprising several future segments. Double-label in situ hybridizations of $w g$ with en could clarify this, but have been technically impossible in Artemia so far. Based on the opposition of $w g$ and en expression across the morphological grooves between large bulge and small bulge (at least in early stage III) and between small bulge and growth cone (throughout stage III) the morphological units at stage III are still parasegments and the morphologically visible indentations (grooves) between them coincide with the parasegment boundaries. I then used the expression of the appendage marker Dll [EMBL:AM774594] to identify the appendage primordia. Dll expression shows that the first appendage primordia are already specified at stage III (Figure 1E). Surprisingly, Dll is expressed in groups of cells anteriorly adjacent to the grooves and thus in front of the parasegment boundary. Thus, the limbs in Artemia ini- tially are parasegmental structures, identical to the parapodia of the annelids (see [7]).

Hejnol and Scholtz [9] have studied limb primordium formation (as marked by Dll protein expression) in the crustaceans Orchestia cavimana and Porcellio scaber. Because in these species the cell lineage is known, these authors were able to demonstrate that the limb primordium starts as a single cell and expands by activation of Dll in adjacent cells. I propose that arthropods use this expansion mechanism to transform their initially parasegmental appendage primordia into segmental appendages after re-segmentation (Figure 1F, upper row). By contrast, annelids do not re-segment and the clonal boundaries of the parasegments are retained as the definite morphological borders between the body units. I suggest that because of this, the restrictive influence of the morphological borders between the parasegments cannot be overcome by the primordia of the parapodia, resulting in a lack of expansion of the primordia (Figure 1F, lower row). This model thus derives the adult arthropod condition from a common body organisation in immature arthropods and annelids by the arthropod-specific processes of re-segmentation and subsequent expansion of the appendage primordium across the parasegment boundary.

In the adult animals arthropodia and parapodia have different positions on the body (segmental versus parasegmental). This argues against their homology. The present data, however, show that the primordia of these appendages have identical positions in the immature animals and thus arguably derive from a common ancestral structure (i.e. they are homologous). This strongly suggests that Urprotostomia, the last common ancestor of annelids and arthropods, was not only already parasegmented $[6,7]$, but also had parasegmental appendages. This also has consequences for the discussion of animal evolution $[10,11]$ because it suggests, that the last common ancestor of the Lophotrochozoa (Urlophotrochozoon) and of the Ecdysozoa (Urecdysozoon) had appendages and the appendage-less forms in both Lophotrochozoa and Ecdysozoa have lost their appendages secondarily (Fig. 2). Data from the Onychophora show that in older embryonic stages en is expressed in the posterior portion of the appendages and thus in a segmental fashion like in arthropods [12]. This suggests that re-segmentation was already present in the Urecdysozoon (see arrow in Fig 2).

\section{Methods}

\section{Artemia culture and fixation}

Artemia franciscana cysts were purchased from Dohse Aquaristik (Grafschaft-Gelsdorf, Germany) and were activated in seawater ( $34 \mathrm{~g}$ seasalt per litre) with constant oxygen supply at $25^{\circ} \mathrm{C}$. Larvae were harvested after 24,48 or 72 hours. Fixation of nauplii proved to be difficult. Best 


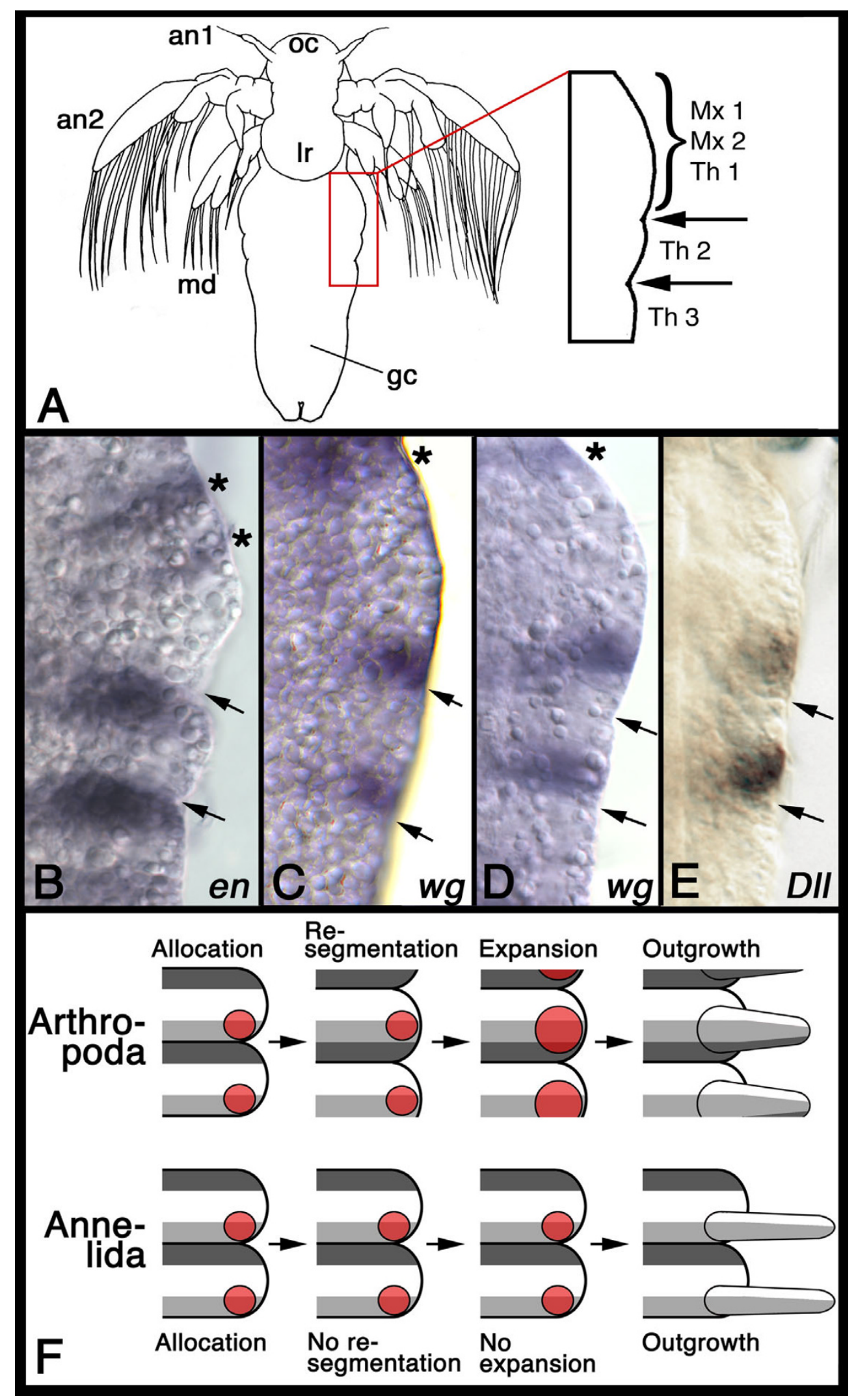

Figure I (see legend on next page) 
Figure I (see previous page)

Parasegments and limb primordia in the brine shrimp Artemia franciscana. (A) Explanatory drawing of a stage III nauplius larva. The anterior part consists of the ocular region (oc), labrum (Ir), first antenna (an I), second antenna (an2) and mandible (md). The part of the trunk that is shown in B, C, and D is boxed in red and magnified. The trunk consist of a large bulge (containing the mesoderm for the presumptive segments of the first and second maxillae $(M \times I, M \times 2)$ and first thoracic appendages (ThI)) and a smaller bulge (containing the mesoderm for the second thoracic segment (Th2)). All following body units form from the growth cone. (B) Expression of engrailed in the anterior trunk. The asterisks denote the engrailed stripes of the future first and second maxillary segment. The engrailed stripes just posterior to the arrows are the stripes of the future first and second thoracic segment. The arrows in B-E point to the grooves between the parasegments. (C-D) Expression of wingless in the anterior trunk. The asterisk denotes the wg stripe of the first maxilla. The second maxilla does not (yet?) express wg. The nauplius in $\mathrm{D}$ is slightly older than the one in $\mathrm{C}$. Note that the expression of wg is not directly anteriorly adjacent to the groove between large and small bulge in the older nauplius. (E) Expression of Distal-less in the anterior trunk reveals that the circle shaped appendage primordia are located anterior to the grooves. (F) Schematic summary of the model of appendage allocation in annelids and arthropods proposed here. Shown are two hemi-parasegments for each animal group, anterior is to the top. See text for details. Dark grey: en expression; light grey: wg expression; red: DII/Dlx expression in the appendage primordia.

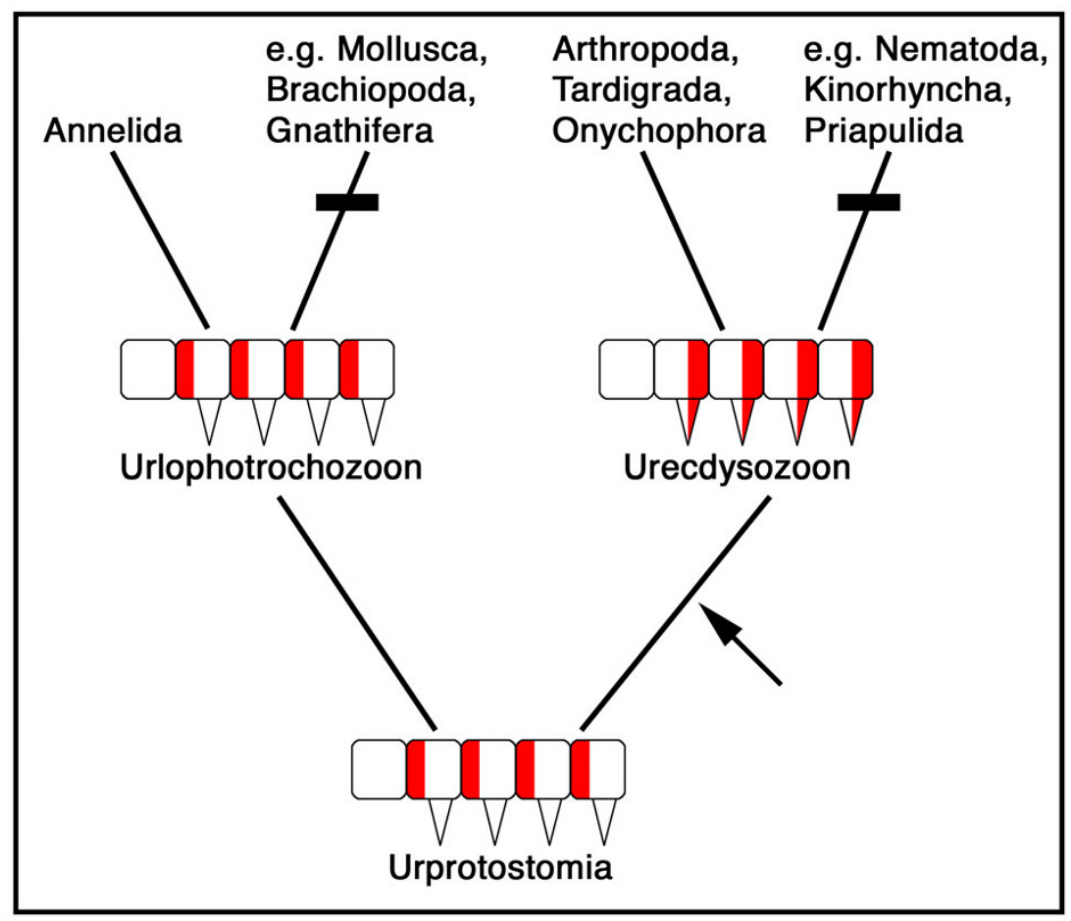

Figure 2

Evolutionary hypothesis for the origin and loss of appendages in the Protostomia. Based on the model shown in Fig. IF, the common ancestor of Lophotrochozoa and Ecdysozoa, termed Urprotostomia [6], was parasegmented and had parasegmental appendages. No change of this ancestral condition is required in the lophotrochan lineage; the ancestral lophotrochozoan ("Urlophotrochozoon") is virtually identical in body organization to Urprotostomia. In the ecdysozoan lineage the processes of re-segmentation and appendage primordium expansion were evolved. This likely happened before the split of all extant ecdysozoans (arrow), based on the arthropod-like expression of en in the appendages of onychophorans [12]; the ancestral ecdysozoan ("Urecdysozoon") thus had already an adult body organization consisting of segments and segmental appendages. The limb-less forms in both Lophotrochozoa and Ecdysozoa must then be derived from limb-bearing forms by secondary loss of appendages (denoted by the black bars). 
results were achieved after washing the nauplii in DanKlorix cleaner (Colgate-Palmolive, Hamburg, Germany) for 5 minutes and subsequent fixation in PEMFAH $(3 \mathrm{ml}$ PEMS, $450 \mu$ l formaldehyde (37\%), $5 \mathrm{ml}$ heptane) at $4{ }^{\circ} \mathrm{C}$ over night. After fixation the nauplii were transferred to methanol and stored at $-20^{\circ} \mathrm{C}$. Best possible tissue fixation was determined to be the case when after the methanol treatment the orange pigment of the nauplius eyes was preserved and the tissue within the appendages was white rather than clear.

\section{In situ hybridisation}

Artemia nauplii were rehydrated stepwise in PBST and then sonicated for 5 seconds with a tip sonifier (Branson Cell Disruptor B15). Sonication was optimal when more than $50 \%$ of all nauplii were destroyed. They were then treated according to the published protocol for Glomeris marginata [13] with the following modifications: acetylation lasted for 1 hour; anti-Dig antibodies were preabsorbed against fixed and sonicated nauplii for 24 hours at $4{ }^{\circ} \mathrm{C}$ in PBST supplemented with $2 \%$ sheep serum.

\section{Gene cloning}

For RNA extraction, cysts were activated in sterilized and filtered sea water and the nauplii were harvested 48 hours later. Total RNA was extracted using the Trizol reagent (Invitrogen). cDNA was synthesized from this total RNA using the SuperScript II system (Invitrogen). The Artemia engrailed gene has been reported previously [14] and a fragment was cloned with gene specific primers designed on the basis of the published sequence [GenBank:X70939]. A fragment of the homeobox of the Artemia Distal-less gene has been cloned using the previously published primers eDP fw, eDP bw, iDP fw and iDP bw [13]. Within this sequence two nested gene specific primers were designed and were used in two subsequent PCR reactions together with the primer DP dlxm1 [13] to amplify a larger portion of the gene that spans from the homeobox to the DLX-1 motif [15]. A fragment of the Artemia wingless gene was cloned using the primers reported previously [4].

\section{Competing interests}

The author declares he has no competing interests.

\section{Acknowledgements}

I thank Diethard Tautz and Wim Damen for support and comments on the manuscript. This work has been funded by the German Research Council (DFG grant PRII09/I-I).

\section{References}

I. Westheide W: Articulata (Gliedertiere). In Spezielle Zoologie, Teil I, Einzeller und Wirbellose Tiere Edited by: Westheide W, Rieger R. Stuttgart, Gustav Fischer Verlag; 1996:350-352.

2. Adoutte A, Balavoine G, Lartillot N, Lespinet O, Prud'homme B, de Rosa $R$ : The new animal phylogeny: reliability and implications. Proc Natl Acad Sci USA 2000, 97:4453-4456.
3. Damen WGM: Evolutionary conservation and divergence of the segmentation process in arthropods. Dev Dyn 2007, 236:1379-1391.

4. Damen WGM: Parasegmental organization of the spider embryo implies that the parasegment is an evolutionary conserved entity in arthropod embryogenesis. Development 2002, I 29:1239-1250.

5. Piepenburg O, Vorbruggen G, Jaeckle H: Drosophila segment borders result from unilateral repression of Hedgehog activity by Wingless signaling. Mol Cell 2000, 6:203-209.

6. Prud'homme B, de Rosa R, Arendt D, Julien JF, Pajaziti R, Dorresteijn AW, Adoutte A, Wittbrodt J, Balavoine G: Arthropod-like expression patterns of engrailed and wingless in the annelid Platynereis dumerilii suggest a role in segment formation. Curr Biol 2003, 13: 1876-|88I.

7. Saudemont A, Dray N, Hudry B, Le Gouar M, Vervoort M, Balavoine $\mathrm{G}$ : Complementary striped expression patterns of NK homeobox genes during segment formation in the annelid Platynereis dumerilii. Dev Biol 2008. doi: 10.1016/j.ydbio.2008.02.013.

8. Benesch R: Zur Ontogenie und Morphologie von Artemia salina L. Zool Jb Anat 1969, 86:307-458.

9. Hejnol A, Scholtz G: Clonal analysis of Distal-less and engrailed expression patterns during early morphogenesis of uniramous and biramous crustacean limbs. Dev Genes Evol 2004, 2 I 4:473-485.

10. Philippe H, Lartillot N, Brinkmann H: Multigene analyses of bilaterian animals corroborate the monophyly of Ecdysozoa, Lophotrochozoa, and Protostomia. Mol Biol Evol 2005, 22: I246-I253.

II. Telford MJ, Bourlat SJ, Economou A, Papillon D, Rota-Stabelli O: The evolution of the Ecdysozoa. Phil Trans $R$ Soc $B$ 2008, 363:1529-1537.

12. Eriksson BJ, Larson ET, Thörnqvist PO, Tait NN, Budd GE: Expression of engrailed in the developing brain and appendages of the onychophoran Euperipatoides kanangrensis (Reid). J exp Zool B (Mol Dev Evol) 2005, 304B:220-228.

13. Prpic NM, Tautz D: The expression of the proximodistal axis patterning genes Distal-less and dachshund in the appendages of Glomeris marginata (Myriapoda: Diplopoda) suggests a special role of these genes in patterning the head appendages. Dev Biol 2003, 260:97-II2.

14. Manzanares M, Marco R, Garesse R: Genomic organization and developmental pattern of expression of the engrailed gene from the brine shrimp Artemia. Development 1993, I 18:1209-1219.

15. Aspöck G, Bürglin TR: The Caenorhabditis elegans Distal-less ortholog ceh-43 is required for development of the anterior hypodermis. Dev Dyn 200I, 222:403-409.

\section{Publish with Bio Med Central and every scientist can read your work free of charge}

"BioMed Central will be the most significant development for disseminating the results of biomedical research in our lifetime. "

Sir Paul Nurse, Cancer Research UK

Your research papers will be:

- available free of charge to the entire biomedical community

- peer reviewed and published immediately upon acceptance

- cited in PubMed and archived on PubMed Central

- yours - you keep the copyright

Submit your manuscript here:

http://www.biomedcentral.com/info/publishing_adv.asp
BioMedcentral 